\title{
Protein Phosphatases and Calcium/Calmodulin-Dependent Protein Kinase II-Dependent Synaptic Plasticity
}

\author{
Roger J. Colbran \\ Department of Molecular Physiology and Biophysics, The Center for Molecular Neuroscience and The Vanderbilt Kennedy Center for Research on Human \\ Development, Vanderbilt University School of Medicine, Nashville, Tennessee 37232-0615
}

Key words: calcium; calmodulin; learning; localization; LTP; NMDA; phosphatase; protein kinase; postsynaptic density

Synaptic plasticity in hippocampal CA1 pyramidal cells requires a delicate balance of protein kinase and protein phosphatase activities. Long-term potentiation (LTP) after intense synaptic stimulation often results from postsynaptic $\mathrm{Ca}^{2+}$ influx via NMDAtype glutamate receptors and activation of multiple protein kinases. In contrast, weaker synaptic stimulation paradigms can induce long-term depression (LTD) (or depotentiation of previous LTP) via NMDA receptor-dependent activation of protein serine/threonine phosphatases. Autophosphorylations at $\mathrm{Thr}^{286}$, $\mathrm{Thr}^{305}$, and $\mathrm{Thr}^{306}$ regulate the activity and subcellular localization of calcium/calmodulin-dependent protein kinase II (CaMKII) and are critical for normal synaptic plasticity, as well as learning-memory (Lisman et al., 2002; Colbran and Brown, 2004; Elgersma et al., 2004; Griffith, 2004; Schulman, 2004). Thus, protein phosphatases acting at these autophosphorylation sites, and at critical phosphorylation sites in other proteins such as AMPA-type glutamate receptors, must also modulate plasticity (for review, see Bear and Malenka, 1994; Winder and Sweatt, 2001; Song and Huganir, 2002). Protein serine/threonine phosphatase catalytic subunits associate with other proteins providing regulatory complexity and dictating the specificity and localization of their activities. This review discusses the composition and regulation of phosphatase complexes identified in hippocampal neurons, as well as their putative roles in modulating CaMKIIdependent synaptic plasticity.

\section{Identity of protein phosphatases}

Protein phosphatase types 1, 2A, 2B, and 2C (PP1, PP2A, PP2B, and $\mathrm{PP} 2 \mathrm{C}$, respectively) account for the majority of serine/threonine phosphatase activity in brain and other tissues (Cohen, 1997). PP1 and PP2A catalytic subunits are constitutively active, whereas PP2B is activated by binding of $\mathrm{Ca}^{2+} /$ calmodulin, and PP2C is $\mathrm{Mg}^{2+}$ dependent. Diverse protein phosphatase complexes are formed by assembly of the catalytic subunits with regulatory and targeting protein subunits. For example, $>60$ heterotrimeric PP2A holoenzymes can be generated by all permutations

Received July 16, 2004; revised Aug. 25, 2004; accepted Aug. 25, 2004.

This work was supported by National Institutes of Health Grants R01-NS37508, R01-MH63232, and P01NS44282. I thank Dr. Danny Winder (Vanderbilt University) and members of my laboratory for many helpful discussions and suggestions.

Correspondence should be addressed to Roger J. Colbran, Department of Molecular Physiology and Biophysics, Vanderbilt University, Nashville, TN 37232-0615. E-mail: roger.colbran@vanderbilt.edu.

D0I:10.1523/JNEUROSCI.3602-04.2004

Copyright $\odot 2004$ Society for Neuroscience $\quad 0270-6474 / 04 / 248404-06 \$ 15.00 / 0$ of the catalytic (C) subunits (two genes) with structural (A) subunits (two genes) and regulatory (B) subunits (four known unrelated gene families), and these can additionally associate with other cellular proteins (Virshup, 2000). Similarly, four PP1 catalytic subunit isoforms $\left(\alpha, \beta, \gamma_{1}\right.$, and $\left.\gamma_{2}\right)$ differentially interact with $>40$ known regulatory and/or targeting subunits (Ceulemans and Bollen, 2004). Thus, to understand how phosphatases modulate processes such as synaptic plasticity, it is critical to identify both the type of phosphatase that dephosphorylates a physiologically relevant substrate and the molecular nature of relevant protein phosphatase complex(es).

\section{Protein phosphatase complexes \\ PP1 complexes}

PP1-binding proteins usually contain a short canonical amino acid sequence (-Arg/Lys-Val/Ile-X-Phe-) that interacts with a conserved hydrophobic groove on the surface of PP1 catalytic subunits (Barford et al., 1998). Secondary interactions usually confer unique regulatory specificity to the interaction (for review, see Bollen, 2001; Cohen, 2002).

The F-actin binding proteins spinophilin (Satoh et al., 1998) and neurabin (Nakanishi et al., 1997) associate with PP1 via canonical PP1-binding motifs (Allen et al., 1997; Hsieh-Wilson et al., 1999). Secondary interaction sites surrounding this motif dictate selective association with PP $1 \alpha$ or PP $1 \gamma_{1}$ over PP $1 \beta$ and also inhibit PP1 activity in vitro (MacMillan et al., 1999; Terry-Lorenzo et al., 2002; Carmody et al., 2004). However, neurabin-PP1 complexes isolated from brain extracts by immunoprecipitation display catalytic activity, suggesting that neurabin-associated PP1 may dephosphorylate colocalized substrates (Oliver et al., 2002). Because the PP1 isoform-binding selectivity of spinophilin and neurabin in vitro matches the selective enrichment of PP1 isoforms in isolated PSDs (postsynaptic densities) (Strack et al., 1997a, 1999; Terry-Lorenzo et al., 2002), it is likely that spinophilin and/or neurabin selectively target PP $1 \alpha$ and $\mathrm{PP} 1 \gamma_{1}$ activity to actin-rich dendritic spines and PSDs. Interestingly, binding of spinophilin to F-actin is inhibited by phosphorylation by PKA (Hsieh-Wilson et al., 2003) or CaMKII (Grossman et al., 2004).

The PP1 complex with spinophilin is necessary for normal regulation of AMPA- and NMDA-type glutamate receptors and synaptic plasticity (Fig. $1 A, B$ ) (Yan et al., 1999; Feng et al., 2000). In addition, both spinophilin and neurabin modulate dendritic spine formation and dynamics (Feng et al., 2000; Oliver et al., 2002), although the molecular mechanisms underlying this function are unclear. 


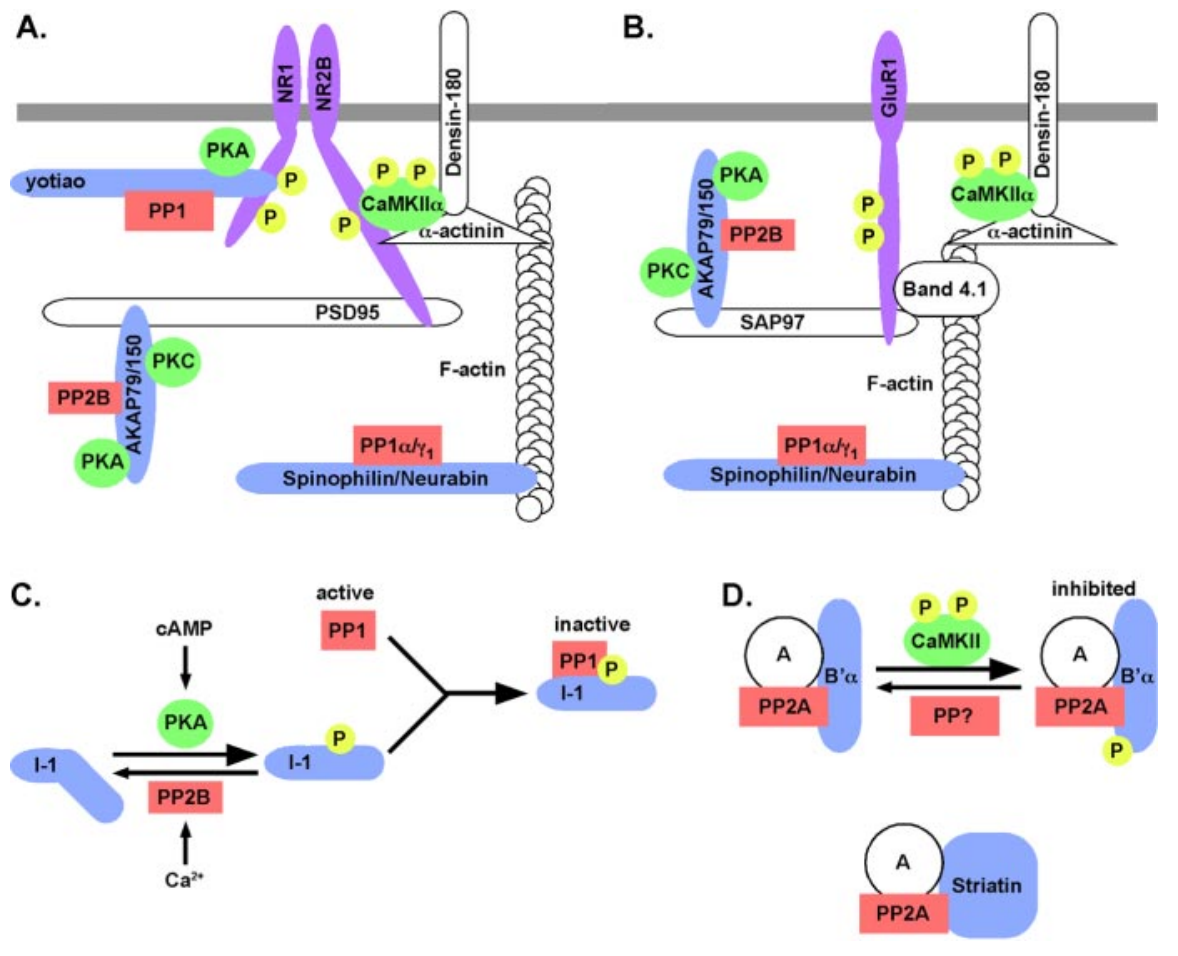

Figure 1. Multiple protein phosphatase complexes regulate CaMKII and glutamate receptors. Putative complexes of PP1 and PP2B catalytic subunits (red) and multiple kinases (green) at NMDA-type $(A)$ and AMPA-type ( $B$ ) glutamate receptors (purple) mediated by scaffolding and cytoskeletal proteins. Protein phosphatase-binding proteins are depicted in blue, whereas other scaffolding and cytoskeletal proteins are white. Phospho-proteins are indicated by the attached yellow circles. Although each protein-protein interaction has been individually demonstrated and some ternary and tertiary subcomplexes verified, complete assembly of the entire complexes has not been demonstrated. C, Regulation of soluble PP1 by phosphorylation- dephosphorylation of inhibitor- 1 by PKA and PP2B, respectively. DARPP-32 (not shown) is a functional homolog of inhibitor- 1 that is regulated by similar mechanisms. D, Dendritic PP2A holoenzymes. Top, Heterotrimeric PP2A holoenzymes containing the $B^{\prime} \alpha$ regulatory subunit are inhibited by CaMKII phosphorylation. Bottom, PP2A holoenzymes containing the striatin regulatory subunit have also been localized to dendrites and PSDS.

The functionally homologous inhibitor-1 and DARPP-32 (dopamine and cAMP-regulated phosphoprotein 32) proteins are differentially expressed in hippocampal subregions (Allen et al., 2000; Svenningsson et al., 2002). Their interactions with PP1 require the canonical PP1-binding motif as well as a region $\mathrm{C}$ terminal to this motif that surrounds their PKA phosphorylation sites. Phosphorylation of inhibitor-1 or DARRP-32 by PKA (at $\mathrm{Thr}^{35}$ and $\mathrm{Thr}^{34}$, respectively) stabilizes the complexes, thereby suppressing PP1 activity (Huang et al., 1999). Dephosphorylation of these sites by PP2B dissociates the complex, increasing PP1 activity. Thus, inhibitor-1 and DARPP-32 permit antagonistic modulation of PP1 activity by cAMP and $\mathrm{Ca}^{2+}$ signaling pathways (Fig. 1C). Several additional kinases and phosphatases act on inhibitor-1 and DARRP-32 to allow multiple neurotransmitters to fine-tune the regulation of this pathway (for review, see Greengard et al., 1999; Svenningsson et al., 2004).

PP1 also binds to other hippocampal proteins, including the NMDA-receptor associated protein yotiao (Westphal et al., 1999), neurofilament-L protein (Terry-Lorenzo et al., 2000), and the nuclear PNUTS protein (PP1 nuclear targeting subunit) (Allen et al., 1998). Yotiao interacts with PP1 independent of an identifiable canonical motif and enhances PP1 activity toward NMDA receptors. However, peptides containing the canonical PP1-binding motif compete for yotiao binding to PP1, suggesting that yotiao interacts with the hydrophobic groove on the catalytic subunit that is typically occupied by the Arg/Lys-Val/Ile-X-Phe motif of other PP1-binding proteins. The functions of the PP1 complexes with neurofilament-L and PNUTS are less clear.

\section{PP2A complexes}

There is enormous potential diversity in the heterotrimeric PP2A holoenzyme complexes (see above), and many of the known PP2A subunits have been identified in hippocampus. However, the roles of specific PP2A holoenzymes or complexes in synaptic regulation are poorly defined. LTP induction enhances CaMKII-mediated phosphorylation of the B' $\alpha$ regulatory subunit of $\mathrm{PP} 2 \mathrm{~A}$, inhibiting CaMKII dephosphorylation (Fig. 1D) (Fukunaga et al., 2000). Striatin is a novel $\mathrm{Ca}^{2+} /$ calmodulin-binding $\mathrm{PP} 2 \mathrm{~A}$ regulatory (B) subunit associated with dendritic spines and PSDs (Moreno et al., 2000). More studies are clearly warranted.

\section{PP2B complexes}

$\mathrm{PP} 2 \mathrm{~B}$ (also known as calcineurin) is the only phosphatase directly modulated by a second messenger $\left(\mathrm{Ca}^{2+}\right.$ acting via calmodulin and the $\mathrm{B}$ regulatory subunit). PP2B has a relatively restricted substrate specificity compared with other phosphatases. Because PP2B is activated at lower $\mathrm{Ca}^{2+} /$ calmodulin concentrations than CaMKII, weak synaptic stimulation may preferentially activate $\mathrm{PP} 2 \mathrm{~B}$, dephosphorylating inhibitor- 1 and thereby activating PP1, whereas stronger stimulation also recruits CaMKII activation (Lisman, 1989). Targeting of PP2B to PSDs can be mediated by binding to AKAP79/150 (Coghlan et al., 1995), a PKA anchoring protein that also binds phosphatidylinositol-4,5bisphosphate, calmodulin, PKC, and F-actin (Dell'Acqua et al., 1998; Gomez et al., 2002). Additional interactions of AKAP79/ 150 with SAP97 (synapse-associated protein 97) or PSD95 mediate association of PP2B with AMPA- and/or NMDA-type glutamate receptors (Fig. 1 $A, B$ ) (Colledge et al., 2000). NMDA receptor activation disrupts the colocalization and coimmunoprecipitation of AKAP79/150 with PSD95 family proteins at synapses in cultured neurons, by a mechanism that involves PP2B activity and rearrangement of the actin cytoskeleton (Gomez et al., 2002). This NMDA-induced redistribution of AKAP79/150 appears to be accompanied by parallel changes in PKA localization and a subcellular redistribution of $\mathrm{PP} 2 \mathrm{~B}$.

\section{Regulation of CaMKII-dependent synaptic plasticity by phosphatases}

LTP induction often requires the (auto)phosphorylation of CaMKII at $\mathrm{Thr}^{286}$ in hippocampus (Lisman et al., 2002; Colbran and Brown, 2004) (see the mini-review in this series by Elgersma et al., titled Mouse Genetic Approaches to Investigating Calcium/ Calmodulin-Dependent Protein Kinase II Function in Plasticity and Cognition). Given the importance of phosphatases in LTD induction, it is perhaps surprising that dephosphorylation of $\mathrm{Thr}^{286}$ has not been demonstrated after LTD or depotentiation 
(reversal of LTP). Moreover, hippocampal LTD induction is normal in CaMKII ${ }^{\text {T286A }}$ mice (Krezel et al., 1999). Nevertheless, the role of CaMKII dephosphorylation in synaptic plasticity is beginning to be understood.

\section{In vitro studies}

PP1, PP2A, and PP2C were shown to dephosphorylate $\mathrm{Thr}^{286}$ of CaMKII in vitro many years ago (Shields et al., 1985; Dosemeci and Reese, 1993; Fukunaga et al., 1993). Recent studies have shown that active PP1 enhances the apparent cooperativity for $\mathrm{Thr}^{286}$ autophosphorylation of CaMKII, resulting in ultrasensitive kinase activation within a tight range of $\mathrm{Ca}^{2+}$ concentrations (Bradshaw et al., 2003). However, it seems likely that this in vitro effect may be exerted by any phosphatase active toward $\mathrm{Thr}^{286}$. In forebrain extracts, PP1 and PP2A account for the majority of phosphatase activity measured using $\mathrm{Thr}^{286}$ autophosphorylated CaMKII (see below) (Strack et al., 1997a). Although PP2C may make only a small contribution to CaMKII dephosphorylation in forebrain (Strack et al., 1997a), it may have more significant roles in cerebellum and other cells (Fukunaga et al., 1993; Ishida et al., 1998; Kitani et al., 1999). Although there is no evidence for dephosphorylation of CaMKII by PP2B, it may indirectly modulate CaMKII by dephosphorylating inhibitor-1 and/or DARPP-32, thereby activating PP1 (see above). PP1, PP2A, and PP2C also can dephosphorylate $\mathrm{Thr}^{305}$ and $\mathrm{Thr}^{306}$ (Patton et al., 1990; Fukunaga et al., 1993).

Although specific phosphatase complexes involved in CaMKII dephosphorylation have not been identified, a novel aspect of CaMKII regulation is that the physiologically relevant phosphatase appears to depend on the subcellular localization of the kinase. CaMKII localization is dynamically regulated by multiple protein-protein interactions (for review, see Colbran, 2004) (see also the mini-reviews in this series by Griffith, titled Regulation of Calcium/Calmodulin-Dependent Protein Kinase II Activation by Intramolecular and Intermolecular Interactions; Schulman, titled Activity-Dependent Regulation of Calcium/CalmodulinDependent Protein Kinase II Localization). CaMKII endogenous to isolated PSDs (i.e., that associated with the PSD in situ) was mostly dephosphorylated by PP1 (Shields et al., 1985; Dosemeci and Reese, 1993; Strack et al., 1997a). However, in whole-brain extracts, PP2A was the major enzyme that dephosphorylated either exogenously added $\mathrm{Thr}^{286}$-autophosphorylated CaMKII or the endogenous soluble kinase (Strack et al., 1997a). In contrast, PP1 was the major activity toward the fraction of endogenous CaMKII associated with the PSD-enriched fraction in the same whole-brain extracts (Strack et al., 1997a). Isolated PSD preparations are highly enriched in PP1 and contain little PP2A (Strack et al., 1997a; Terry-Lorenzo et al., 2000), but, when purified soluble $\mathrm{Thr}^{286}$-autophosphorylated CaMKII was added to isolated PSDs, the PP2A made the major contribution to its dephosphorylation (Strack et al., 1997b). However, a fraction of the added kinase binds to the isolated PSDs; when this PSD-associated pool of added kinase was analyzed separately, PP1 was responsible for the dephosphorylation (Strack et al., 1997b). Thus, association with PSDs enhances PP1-mediated dephosphorylation of CaMKII or protects it from PP2A-mediated dephosphorylation. The colocalization with PSD-associated PP1 or sequestration away from PP2A may be attributable to CaMKII interactions with specific PSD proteins, resulting in differential modulation of $\mathrm{Thr}^{286}$ dephosphorylation.

\section{Regulation by PP1 complexes in situ}

Several studies implicate targeted PP1 complexes in synaptic plasticity. Intracellular perfusion of peptides based on the canonical PP1-binding motif has no effect on basal synaptic transmission but blocks hippocampal LTD. Moreover, synaptic activation of NMDA receptors in cultured hippocampal neurons increases the proportion of total synapses that contain PP1 (Morishita et al., 2001). Although these data suggest that targeted PP1 is important for synaptic plasticity, the impact of NMDA receptor activation on the localizations of spinophilin and other PP1binding proteins are not known. However, PSD-associated spinophilin is relatively dephosphorylated when compared with spinophilin found in soluble or synaptic plasma membrane fractions, suggesting that phosphorylation of spinophilin by PKA and/or CaMKII may dissociate spinophilin from synapses (Hsieh-Wilson et al., 2003; Grossman et al., 2004). Thus, spinophilin dephosphorylation may drive increased synaptic localization, thereby increasing the amount of synaptic PP1. Interestingly, spinophilin knock-out mice exhibit a strong deficit in hippocampal LTD but no deficit in LTP induced by strong synaptic stimulation (two times for $1 \mathrm{sec}$ each at $100 \mathrm{~Hz}$ ) (Feng et al., 2000). Although this study specifically implicates PP1 targeting by spinophilin in synaptic plasticity, the consequences of spinophilin deficiency on $\mathrm{Thr}^{286}$ autophosphorylation of CaMKII, phosphorylation of other proteins involved in hippocampal synaptic plasticity, LTP induced using other paradigms, and on learning and memory have not been reported.

Saturation of PSD-associated PP1 after translocation of $\mathrm{Thr}^{286}$-autophosphorylated CaMKII to the PSD has been proposed to permit sustained $\mathrm{Thr}^{286}$ autophosphorylation after LTP induction (Lisman and Zhabotinsky, 2001). Consistent with this model, one series of studies suggests that inhibition of PP1 allows for increased $\mathrm{Thr}^{286}$ autophosphorylation as well as LTP induction. Moderate theta burst stimulation paradigms were insufficient to induce LTP in hippocampal slices unless paired with cAMP-inducing stimuli, which enhanced inhibitor-1 phosphorylation at the PKA site and decreased PP1 activity. In parallel, $\mathrm{Thr}^{286}$ phosphorylation of CaMKII was induced only when the two stimuli were paired. Inhibition of PP1 was therefore suggested to "gate" CaMKII autophosphorylation at $\mathrm{Thr}^{286}$ in this LTP paradigm (Blitzer et al., 1998; Brown et al., 2000). Thus, potentiation of LTP induction by $\beta$-adrenergic receptor agonists (Thomas et al., 1996; Winder et al., 1999; Brown et al., 2000; Yang et al., 2002) and other CAMP-coupled neurotransmitter receptors (Otmakhova and Lisman, 1996; Cai et al., 2002; Svenningsson et al., 2002; Li et al., 2003; Wang et al., 2003) may require PP1 inhibition by inhibitor-1 (or DARPP-32) to enhance CaMKII autophosphorylation.

The roles of PP1 and inhibitor-1 in hippocampal plasticity have also been addressed using transgenic mice. Inducible overexpression of a constitutively active mutant of inhibitor-1 (caI-1) (with the $\mathrm{Thr}^{35}$ phosphorylation site mutated to aspartate to mimic PKA phosphorylation) suppresses PP1 activity and enhances the phosphorylation of CaMKII at $\mathrm{Thr}^{286}$, AMPA receptors (Ser ${ }^{831}$ in GluR1), and the CREB (cAMP response elementbinding protein) transcription factor (Genoux et al., 2002). These studies are consistent with a role for PP1 in gating CaMKII autophosphorylation. Moreover, the caI-1 mice displayed enhanced learning and memory in object recognition and water maze tasks, but changes in hippocampal synaptic plasticity were not investigated.

Given the caI-1 data mentioned above, it initially seems surprising that inhibitor-1 knock-out mice have normal LTP in the CA1 region of hippocampus and normal spatial memory in the 
water maze (Allen et al., 2000). These inconsistencies in defining a role for inhibitor- 1 in the CA1 region may reflect differences in the LTP induction protocols (theta burst vs $100 \mathrm{~Hz}$ tetanic stimulation) and in the behavioral tests used. Alternatively, low levels of DARRP-32 may compensate for inhibitor-1 deficiency in the CA1 region. Interestingly, inhibitor-1 is expressed at much higher levels in the dentate gyrus than in the CA1, and inhibitor-1 knock-out animals exhibit defective LTP in the dentate gyrus (Allen et al., 2000). Thus, PP1 regulation by inhibitor-1 may be essential for plasticity in dentate gyrus but only modulatory in CA1. It will be important to reanalyze synaptic plasticity in the CA1 region using theta burst stimulation combined with PKA activation (see above) and establish the impact of inhibitor-1 knock-out on $\mathrm{Thr}^{286}$ autophosphorylation.

\section{Regulation by PP2A}

PP2A also has been suggested to control CaMKII-dependent synaptic plasticity. Induction of LTP decreased PP2A activity measured in hippocampal CA1 homogenates using $\mathrm{Thr}^{286}$ autophosphorylated CaMKII as substrate (Fukunaga et al., 2000). This inhibition of PP2A required CaMKII activation and was associated with phosphorylation of the B' $\alpha$ regulatory subunit of the PP2A holoenzyme. Reduced PP2A activity may contribute to the sustained phosphorylation of CaMKII at Thr ${ }^{286}$ or of other sites/proteins after LTP induction.

A mouse model of Angelman's mental retardation syndrome created by deletion of the $u b e 3 a$ ubiquitin ligase displayed enhanced basal phosphorylation of CaMKII at $\mathrm{Thr}^{286}$ and $\mathrm{Thr}^{305}$ in hippocampal homogenates, correlating with impairments in hippocampal synaptic plasticity and learning (Weeber et al., 2003) (see the mini-review in this series by Elgersma et al., titled Mouse Genetic Approaches to Investigating Calcium/CalmodulinDependent Protein Kinase II Function in Plasticity and Cognition). Hippocampal homogenates also contained reduced protein phosphatase activity. Although these studies did not specifically identify the phosphatase activity (Weeber et al., 2003), the phosphopeptide substrate used is generally considered PP2A selective. Interestingly, recent work in Drosophila provided genetic evidence for PP2A-mediated dephosphorylation of $\mathrm{Thr}^{306}$ (equivalent to $\mathrm{Thr}^{305}$ in mammalian CaMKII) in vivo (Lu et al., 2003). If PP2A also dephosphorylates $\mathrm{Thr}^{305}$ and $\mathrm{Thr}^{306}$ in mammals, it is possible that reduced PP2A activity in the mouse model of Angelman's syndrome results in enhanced CaMKII autophosphorylation at $\mathrm{Thr}^{305 / 306}$ and/or $\mathrm{Thr}^{286}$. However, the molecular link from deletion of the $u b e 3 a$ gene to the reduction in protein phosphatase activity remains unclear.

\section{Regulation by PP2B}

Genetic manipulation of hippocampal PP2B activity by inducible transgenic overexpression of a constitutively active PP2B (Winder et al., 1998) or a specific PP2B inhibitor peptide (Malleret et al., 2001) reversibly affects hippocampal synaptic plasticity. Facilitation of LTP when PP2B activity is reduced, and inhibition of LTP when PP2B activity is increased, may be explained in part by changes in the phosphorylation of inhibitor-1 and/or CaMKII, although this was not directly tested. The impact of PP2B binding to AKAP79 on synaptic plasticity is unknown, although this complex facilitates regulation of AMPA receptors in a manner reminiscent of LTD (Tavalin et al., 2002).

\section{Summary and perspectives}

Several protein phosphatase complexes have been identified in hippocampal neurons, but there likely remain a greater diversity to be discovered. One major challenge is to determine how the formation of this often-bewildering array of phosphatase complexes is regulated in situ. Nevertheless, it seems likely that these complexes provide for diversity and subtlety in modulating synaptic transmission and other neuronal processes. The roles of certain protein phosphatase complexes in modulating CaMKIIdependent signaling and some forms of plasticity are beginning to be understood, but there remains much to be learned.

\section{References}

Allen PB, Ouimet CC, Greengard P (1997) Spinophilin, a novel protein phosphatase 1 binding protein localized to dendritic spines. Proc Natl Acad Sci USA 94:9956-9961.

Allen PB, Kwon YG, Nairn AC, Greengard P (1998) Isolation and characterization of PNUTS, a putative protein phosphatase 1 nuclear targeting subunit. J Biol Chem 273:4089-4095.

Allen PB, Hvalby O, Jensen V, Errington ML, Ramsay M, Chaudhry FA, Bliss TV, Storm-Mathisen J, Morris RG, Andersen P, Greengard P (2000) Protein phosphatase-1 regulation in the induction of long-term potentiation: heterogeneous molecular mechanisms. J Neurosci 20:3537-3543.

Barford D, Das AK, Egloff MP (1998) The structure and mechanism of protein phosphatases: insights into catalysis and regulation. Annu Rev Biophys Biomol Struct 27:133-164.

Bear MF, Malenka RC (1994) Synaptic plasticity: LTP and LTD. Curr Opin Neurobiol 4:389-399.

Blitzer RD, Connor JH, Brown GP, Wong T, Shenolikar S, Iyengar R, Landau EM (1998) Gating of CaMKII by cAMP-regulated protein phosphatase activity during LTP. Science 280:1940-1942.

Bollen M (2001) Combinatorial control of protein phosphatase-1. Trends Biochem Sci 26:426-431.

Bradshaw JM, Kubota Y, Meyer T, Schulman H (2003) An ultrasensitive $\mathrm{Ca}^{2+} /$ calmodulin-dependent protein kinase II-protein phosphatase 1 switch facilitates specificity in postsynaptic calcium signaling. Proc Natl Acad Sci USA 100:10512-10517.

Brown GP, Blitzer RD, Connor JH, Wong T, Shenolikar S, Iyengar R, Landau EM (2000) Long-term potentiation induced by theta frequency stimulation is regulated by a protein phosphatase-1-operated gate. J Neurosci 20:7880-7887.

Cai X, Gu Z, Zhong P, Ren Y, Yan Z (2002) Serotonin 5-HT1A receptors regulate AMPA receptor channels through inhibiting $\mathrm{Ca}^{2+} /$ calmodulindependent kinase II in prefrontal cortical pyramidal neurons. J Biol Chem 277:36553-36562.

Carmody LC, Bauman PA, Bass MA, Mavila N, DePaoli-Roach AA, Colbran RJ (2004) A protein phosphatase-1gammal isoform selectivity determinant in dendritic spine-associated neurabin. J Biol Chem 279:21714-21723.

Ceulemans H, Bollen M (2004) Functional diversity of protein phosphatase-1, a cellular economizer and reset button. Physiol Rev 84:1-39.

Coghlan VM, Perrino BA, Howard M, Langeberg LK, Hicks JB, Gallatin WM, Scott JD (1995) Association of protein kinase A and protein phosphatase 2B with a common anchoring protein. Science 267:108-111.

Cohen PT (1997) Novel protein serine/threonine phosphatases: variety is the spice of life. Trends Biochem Sci 22:245-251.

Cohen PT (2002) Protein phosphatase 1-targeted in many directions. J Cell Sci 115:241-256.

Colbran RJ (2004) Targeting of calcium/calmodulin-dependent protein kinase II. Biochem J 378:1-16.

Colbran RJ, Brown AM (2004) Calcium/calmodulin-dependent protein kinase II and synaptic plasticity. Curr Opin Neurobiol 14:318-327.

Colledge M, Dean RA, Scott GK, Langeberg LK, Huganir RL, Scott JD (2000) Targeting of PKA to glutamate receptors through a MAGUK-AKAP complex. Neuron 27:107-119.

Dell'Acqua ML, Faux MC, Thorburn J, Thorburn A, Scott JD (1998) Membrane-targeting sequences on AKAP79 bind phosphatidylinositol-4, 5-bisphosphate. EMBO J 17:2246-2260.

Dosemeci A, Reese TS (1993) Inhibition of endogenous phosphatase in a postsynaptic density fraction allows extensive phosphorylation of the major postsynaptic density protein. J Neurochem 61:550-555. 
Elgersma Y, Sweatt JD, Giese KP (2004) Mouse genetic approaches to investigating calcium/calmodulin-dependent protein kinase II function in plasticity and cognition. J Neurosci 24:8410-8415.

Feng J, Yan Z, Ferreira A, Tomizawa K, Liauw JA, Zhuo M, Allen PB, Ouimet CC, Greengard P (2000) Spinophilin regulates the formation and function of dendritic spines. Proc Natl Acad Sci USA 97:9287-9292.

Fukunaga K, Kobayashi T, Tamura S, Miyamoto E (1993) Dephosphorylation of autophosphorylated $\mathrm{Ca}^{2+} /$ calmodulin-dependent protein kinase II by protein phosphatase 2C. J Biol Chem 268:133-137.

Fukunaga K, Muller D, Ohmitsu M, Bako E, DePaoli-Roach AA, Miyamoto E (2000) Decreased protein phosphatase 2A activity in hippocampal longterm potentiation. J Neurochem 74:807-817.

Genoux D, Haditsch U, Knobloch M, Michalon A, Storm D, Mansuy IM (2002) Protein phosphatase 1 is a molecular constraint on learning and memory. Nature 418:970-975.

Gomez LL, Alam S, Smith KE, Horne E, Dell'Acqua ML (2002) Regulation of A-kinase anchoring protein 79/150-cAMP-dependent protein kinase postsynaptic targeting by NMDA receptor activation of calcineurin and remodeling of dendritic actin. J Neurosci 22:7027-7044.

Greengard P, Allen PB, Nairn AC (1999) Beyond the dopamine receptor: the DARPP-32/protein phosphatase-1 cascade. Neuron 23:435-447.

Griffith LC (2004) Regulation of calcium/calmodulin-dependent protein kinase II activation by intramolecular and intermolecular interactions. J Neurosci 24:8394-8398.

Grossman SD, Futter M, Snyder GL, Allen PB, Nairn AC, Greengard P, HsiehWilson LC (2004) Spinophilin is phosphorylated by $\mathrm{Ca} /$ calmodulindependent protein kinase II resulting in regulation of its binding to F-actin. J Neurochem 90:317-324.

Hsieh-Wilson LC, Allen PB, Watanabe T, Nairn AC, Greengard P (1999) Characterization of the neuronal targeting protein spinophilin and its interactions with protein phosphatase-1. Biochemistry 38:4365-4373.

Hsieh-Wilson LC, Benfenati F, Snyder GL, Allen PB, Nairn AC, Greengard P (2003) Phosphorylation of spinophilin modulates its interaction with actin filaments. J Biol Chem 278:1186-1194.

Huang HB, Horiuchi A, Watanabe T, Shih SR, Tsay HJ, Li HC, Greengard P, Nairn AC (1999) Characterization of the inhibition of protein phosphatase-1 by DARPP-32 and inhibitor-2. J Biol Chem 274: $7870-7878$.

Ishida A, Kameshita I, Fujisawa H (1998) A novel protein phosphatase that dephosphorylates and regulates $\mathrm{Ca}^{2+} /$ calmodulin-dependent protein kinase II. J Biol Chem 273:1904-1910.

Kitani T, Ishida A, Okuno S, Takeuchi M, Kameshita I, Fujisawa H (1999) Molecular cloning of $\mathrm{Ca}^{2+} /$ calmodulin-dependent protein kinase phosphatase. J Biochem (Tokyo) 125:1022-1028.

Krezel W, Giese KP, Silva AJ, Chapman PF (1999) Long-term depression is unimpaired in hippocampus of adult aCaMKIIT286A mice. Soc Neurosci Abstr 25:987.

Li S, Cullen WK, Anwyl R, Rowan MJ (2003) Dopamine-dependent facilitation of LTP induction in hippocampal CA1 by exposure to spatial novelty. Nat Neurosci 6:526-531.

Lisman J (1989) A mechanism for the Hebb and the anti-Hebb processes underlying learning and memory. Proc Natl Acad Sci USA 86:9574-9578.

Lisman J, Schulman H, Cline H (2002) The molecular basis of CaMKII function in synaptic and behavioural memory. Nat Rev Neurosci 3:175-190.

Lisman JE, Zhabotinsky AM (2001) A model of synaptic memory: a CaMKII/PP1 switch that potentiates transmission by organizing an AMPA receptor anchoring assembly. Neuron 31:191-201.

Lu CS, Hodge JJ, Mehren J, Sun XX, Griffith LC (2003) Regulation of the $\mathrm{Ca}^{2+} /$ CaM-responsive pool of CaMKII by scaffold-dependent autophosphorylation. Neuron 40:1185-1197.

MacMillan LB, Bass MA, Cheng N, Howard EF, Tamura M, Strack S, Wadzinski BE, Colbran RJ (1999) Brain actin-associated protein phosphatase 1 holoenzymes containing spinophilin, neurabin, and selected catalytic subunit isoforms. J Biol Chem 274:35845-35854.

Malleret G, Haditsch U, Genoux D, Jones MW, Bliss TV, Vanhoose AM, Weitlauf C, Kandel ER, Winder DG, Mansuy IM (2001) Inducible and reversible enhancement of learning, memory, and long-term potentiation by genetic inhibition of calcineurin. Cell 104:675-686.

Moreno CS, Park S, Nelson K, Ashby D, Hubalek F, Lane WS, Pallas DC (2000) WD40 repeat proteins striatin and S/G(2) nuclear autoantigen are members of a novel family of calmodulin-binding proteins that associate with protein phosphatase 2A. J Biol Chem 275:5257-5263.

Morishita W, Connor JH, Xia H, Quinlan EM, Shenolikar S, Malenka RC (2001) Regulation of synaptic strength by protein phosphatase 1 . Neuron 32:1133-1148.

Nakanishi H, Obaishi H, Satoh A, Wada M, Mandai K, Satoh K, Nishioka H, Matsuura Y, Mizoguchi A, Takai Y (1997) Neurabin: a novel neural tissue-specific actin filament-binding protein involved in neurite formation. J Cell Biol 139:951-961.

Oliver CJ, Terry-Lorenzo RT, Elliott E, Bloomer WA, Li S, Brautigan DL, Colbran RJ, Shenolikar S (2002) Targeting protein phosphatase 1 (PP1) to the actin cytoskeleton: the neurabin I/PP1 complex regulates cell morphology. Mol Cell Biol 22:4690-4701.

Otmakhova NA, Lisman JE (1996) $\mathrm{D}_{1} / \mathrm{D}_{5}$ dopamine receptor activation increases the magnitude of early long-term potentiation at CA1 hippocampal synapses. J Neurosci 16:7478-7486.

Patton BL, Miller SG, Kennedy MB (1990) Activation of type II calcium/ calmodulin-dependent protein kinase by $\mathrm{Ca}^{2+} /$ calmodulin is inhibited by autophosphorylation of threonine within the calmodulin-binding domain. J Biol Chem 265:11204-11212.

Satoh A, Nakanishi H, Obaishi H, Wada M, Takahashi K, Satoh K, Hirao K, Nishioka H, Hata Y, Mizoguchi A, Takai Y (1998) Neurabin-II/spinophilin: an actin-filament-binding protein with one PDZ domain localized at cadherin-based cell-cell adhesion sites. J Biol Chem 273:34703475 .

Schulman H (2004) Activity-dependent regulation of calcium/calmodulindependent protein kinase II localization. J Neurosci 24:8399-8403.

Shields SM, Ingebritsen TS, Kelly PT (1985) Identification of protein phosphatase 1 in synaptic junctions: dephosphorylation of endogenous calmodulin-dependent kinase II and synapse-enriched phosphoproteins. J Neurosci 5:3414-3422.

Song I, Huganir RL (2002) Regulation of AMPA receptors during synaptic plasticity. Trends Neurosci 25:578-588.

Strack S, Barban MA, Wadzinski BE, Colbran RJ (1997a) Differential inactivation of postsynaptic density-associated and soluble $\mathrm{Ca}^{2+}$ / calmodulin-dependent protein kinase II by protein phosphatases 1 and 2A. J Neurochem 68:2119-2128.

Strack S, Choi S, Lovinger DM, Colbran RJ (1997b) Translocation of autophosphorylated calcium/calmodulin-dependent protein kinase II to the postsynaptic density. J Biol Chem 272:13467-13470.

Strack S, Kini S, Ebner FF, Wadzinski BE, Colbran RJ (1999) Differential cellular and subcellular localization of protein phosphatase 1 isoforms in brain. J Comp Neurol 413:373-384.

Svenningsson P, Tzavara ET, Witkin JM, Fienberg AA, Nomikos GG, Greengard P (2002) Involvement of striatal and extrastriatal DARPP-32 in biochemical and behavioral effects of fluoxetine (Prozac). Proc Natl Acad Sci USA 99:3182-3187.

Svenningsson P, Nishi A, Fisone G, Girault JA, Nairn AC, Greengard P (2004) DARPP-32: an integrator of neurotransmission. Annu Rev Pharmacol Toxicol 44:269-296.

Tavalin SJ, Colledge M, Hell JW, Langeberg LK, Huganir RL, Scott JD (2002) Regulation of GluR1 by the A-kinase anchoring protein 79 (AKAP79) signaling complex shares properties with long-term depression. J Neurosci 22:3044-3051.

Terry-Lorenzo RT, Inoue M, Connor JH, Haystead TA, Armbruster BN, Gupta RP, Oliver CJ, Shenolikar S (2000) Neurofilament-L is a protein phosphatase-1-binding protein associated with neuronal plasma membrane and post-synaptic density. J Biol Chem 275:2439-2446.

Terry-Lorenzo RT, Carmody LC, Voltz JW, Connor JH, Li S, Smith FD, Milgram SL, Colbran RJ, Shenolikar S (2002) The neuronal actinbinding proteins, neurabin I and neurabin II, recruit specific isoforms of protein phosphatase-1 catalytic subunits. J Biol Chem 277:27716-27724.

Thomas MJ, Moody TD, Makhinson M, O’Dell TJ (1996) Activitydependent beta-adrenergic modulation of low frequency stimulation induced LTP in the hippocampal CA1 region. Neuron 17:475-482.

Virshup DM (2000) Protein phosphatase 2A: a panoply of enzymes. Curr Opin Cell Biol 12:180-185.

Wang X, Zhong P, Gu Z, Yan Z (2003) Regulation of NMDA receptors by dopamine $\mathrm{D}_{4}$ signaling in prefrontal cortex. J Neurosci 23:9852-9861.

Weeber EJ, Jiang YH, Elgersma Y, Varga AW, Carrasquillo Y, Brown 
SE,Christian JM, Mirnikjoo B, Silva A, Beaudet AL, Sweatt JD (2003) Derangements of hippocampal calcium/calmodulin-dependent protein kinase II in a mouse model for Angelman mental retardation syndrome. J Neurosci 23:2634-2644.

Westphal RS, Tavalin SJ, Lin JW, Alto NM, Fraser ID, Langeberg LK, Sheng M, Scott JD (1999) Regulation of NMDA receptors by an associated phosphatase-kinase signaling complex. Science 285:93-96.

Winder DG, Sweatt JD (2001) Roles of serine/threonine phosphatases in hippocampal synaptic plasticity. Nat Rev Neurosci 2:461-474.

Winder DG, Mansuy IM, Osman M, Moallem TM, Kandel ER (1998) Genetic and pharmacological evidence for a novel, intermediate phase of long-term potentiation suppressed by calcineurin. Cell 92:25-37.
Winder DG, Martin KC, Muzzio IA, Rohrer D, Chruscinski A, Kobilka B, Kandel ER (1999) ERK plays a regulatory role in induction of LTP by theta frequency stimulation and its modulation by beta-adrenergic receptors. Neuron 24:715-726.

Yan Z, Hsieh-Wilson L, Feng J, Tomizawa K, Allen PB, Fienberg AA, Nairn AC, Greengard P (1999) Protein phosphatase 1 modulation of neostriatal AMPA channels: regulation by DARPP-32 and spinophilin. Nat Neurosci 2:13-17.

Yang HW, Lin YW, Yen CD, Min MY (2002) Change in bi-directional plasticity at CA1 synapses in hippocampal slices taken from 6-hydroxydopaminetreated rats: the role of endogenous norepinephrine. Eur J Neurosci 16: 1117-1128. 